\title{
HYDROLOGICAL MODELING APPLIED WITH THE IPH2 MODEL IN THE RIVER POXIM AÇU RIO SUB-BASIN, BRAZIL
}

\author{
RICARDO MONTEIRO ROCHA, JOSÉ ESPINOLA JR, FÁBIO WENDELL GRAÇA NUNES, \\ JEAN HENRIQUE MENEZES NASCIMENTO \& IGOR DO NASCIMENTO SANTOS \\ Federal Institute of Education, Science and Technology of Sergipe, Brazil
}

\begin{abstract}
A hydrological model is one of the tools developed by science to better understand and represent the behavior of the river basin. The IPH2 model aims to use it for projects in urban and rural basins. It is a model that uses few parameters and it is based on known methodologies. The objective of the research was to analyze the hydrological flow behavior in the Poxim Açu River sub-basin through modeling with the IPH2 model, as well as to model the flow of the Poxim River basin with a model that does not require a lot of input data and to calibrate the IPH2 model for the studied basin. After the automatic and manual calibration phases, parameters for hydrological simulation were found. After the simulation, the value found for NSE was 0.73 for the coefficient of determination (RSR) the value generated was 0.74 , PBIAS found after calibration was -7.44 , the value of the RMSE was 0.95 , and the RSR value found was 0.07 . According to the results of the present study, it was possible to conclude that the calibration process for the flow behavior of the Poxim-Açu River basin responds positively to what the literature considers satisfactory.

Keywords: hydrological modeling, hydrographic basin, IPH2, hydrology, water resources.
\end{abstract}

\section{INTRODUCTION}

A hydrological model is one of the tools developed by science to better understand and represent the behavior of the river basin and to predict different conditions from those observed [1]. There are limitations to the hydrological simulation, among them the physical heterogeneity of the basin and the number of processes involved. These limitations have contributed to the emergence of a large number of models that differ according to the input parameters used by discretization and to the results to be achieved. The model is not the system but a system study tool. Simulation is the process of using the model. The management of water resources emphasizes the hydrological cycle aspect contemplating in the environmental, climatological, social, hydrological and economic spheres. Reconciling water availability with the quality and quantity characteristics of the demand of a given region is the main objective of integrated water resources management. The hydrological models developed perform the task of representing the system so that the behavior can be studied when some variables are modified, for example, changes in the operating rules of a reservoir increasing or decreasing the downstream flows [2].

The IPH models are models developed at the Hydraulic Research Institute of the Federal University of Rio Grande do Sul in order to simulate part of the hydrological cycle. There are four versions of the model and these are applicable to different situations. The IPH2 model aims to use it for projects in urban and rural basins. It is a model that uses few parameters and is based on known methodologies. The model is applied in basins that do not need propagation of the river bed or that it is irrelevant. The propagation that the model considers refers only to the surface runoff. The model was refined by professors of the UFRGS and added to it other algorithms like the algorithm of infiltration among others. The composition of the current version of the model consists of the algorithms of losses by evaporation and interception, separation of surface and underground flow, propagation of 
surface runoff, underground propagation and optimization of parameters. In order to initialize the model it is necessary to enter with data of $S(\mathrm{t}=0)$, Qsubt $(\mathrm{t}=0), Q s(\mathrm{t}=0)$. It is considered that the basin is in drought and the superficial flow does not exist $Q s(\mathrm{t}=0)=0$ and Qsubt $(\mathrm{t}=0)=Q o b s$, where Qobs is the observed flow at the beginning of the simulation. QobsQobs is known in the adjustment period. In other intervals, the value of the initial desired flow rate for hydrograph simulation is given. Even within the dry season it is assumed that the underground flow and the upper soil layer are in steady state and $T=\operatorname{Qobs}(\mathrm{t}=0)$. The estimate of $S(\mathrm{t}=0)$ is made based on eqn (1).

$$
S=\frac{I_{0}}{\ln h I_{b}} T(t)
$$

The objective of the research was to analyze the hydrological flow behavior in the Poxim Açu River sub-basin through modeling with the IPH2 model, as well as to model the flow of the Poxim River basin with a model that does not require a lot of input data and to calibrate IPH2 model for the studied area.

This study was carried out by high school students of the Federal Institute of Sergipe as a scientific initiation project of the IFS/PETROBRAS Agreement.

\section{MATERIAL AND METHODS}

The catchment area of the Poxim Açu River is a basin belonging to the Sergipe River basin, located between the coasts $10^{\circ} 48^{\prime}$ and $10^{\circ} 56^{\prime}$ south latitude and $37^{\circ} 24^{\prime}$ and $37^{\circ} 10^{\prime}$ 'west longitude.

The basin has in its length approximately $26.6 \mathrm{~km}$ and an area of approximately $128 \mathrm{~km}^{2}$, when its mouth is delimited at a spot on its bed near its confluence with the river Poxim Mirim, according to Fig. 1.

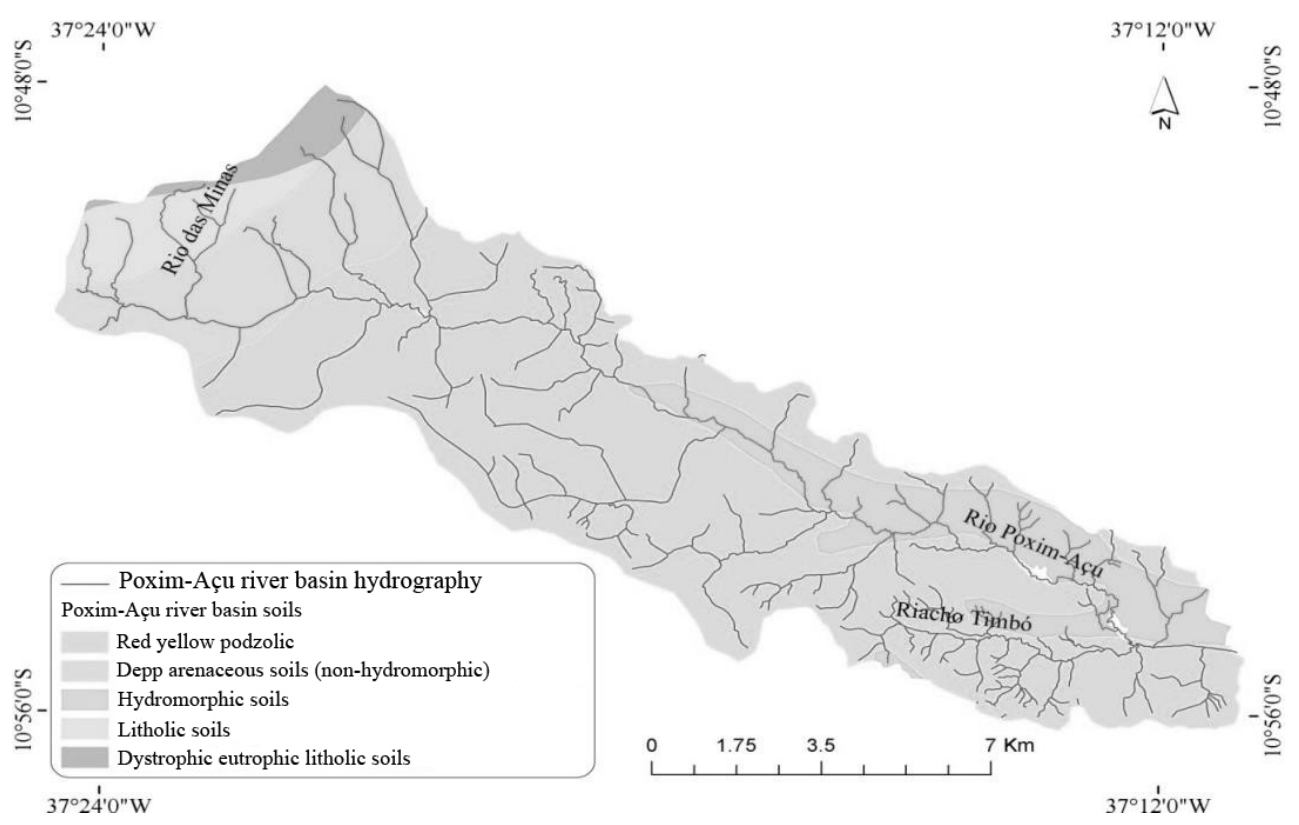

Figure 1: Poxim-Açu river basin. (Source: adapted from the Digital Atlas of Sergipe, 09/2012.) 
In order to monitor the flow and rainfall in the basin, an automatic hydrological station that measures several variables, including precipitation and water level, was used. Data collected every 15 minutes is transmitted to a digital storage unit, the Datalogger. The station is located on the banks of the Poxim-açu river, within the São Cristóvão campus of IFS (Federal Institute of Sergipe), and is composed of a water level height meter, a level sensor, this is an analogue piezoelectric sensor which records the water level through the pressure difference to which it is being subjected. There is also a pluviometer of the brand JCTM, model SP-3, and a datalogger, of the Global Water brand, model GW 500. To calibrate the model, it was used the flow data collected [3] between January 1, 2012 and June 30, 2012. To obtain the evaporation data, the method proposed by SOUZA and SILVA (2013) was used. The data of maximum and minimum daily temperatures, relative humidity (maximum and minimum daily), average global solar radiation, average wind speed were obtained in the automatic station of Inmet in Aracaju - SE. Rainfall data were obtained through the Inmet rainfall station in Aracaju.

\section{RESULTS AND DISCUSSION}

The model input parameters that were found after the automatic and manual calibration phases are shown in Table 1.

Fig. 2 shows the program screen with the model already calibrated.

Table 1: IPH2 model input parameters, after calibration.

\begin{tabular}{ll}
\hline $\mathrm{Io}$ & $=82.4506$ \\
\hline $\mathrm{Ib}$ & $=3.7879$ \\
\hline $\mathrm{H}$ & $=0.4205577970$ \\
\hline $\mathrm{Ks}$ & $=0.7392$ \\
\hline Ksub & $=110.6378$ \\
\hline Rmax & $=1.7000$ \\
\hline Alfa & $=19.9999$ \\
\hline
\end{tabular}

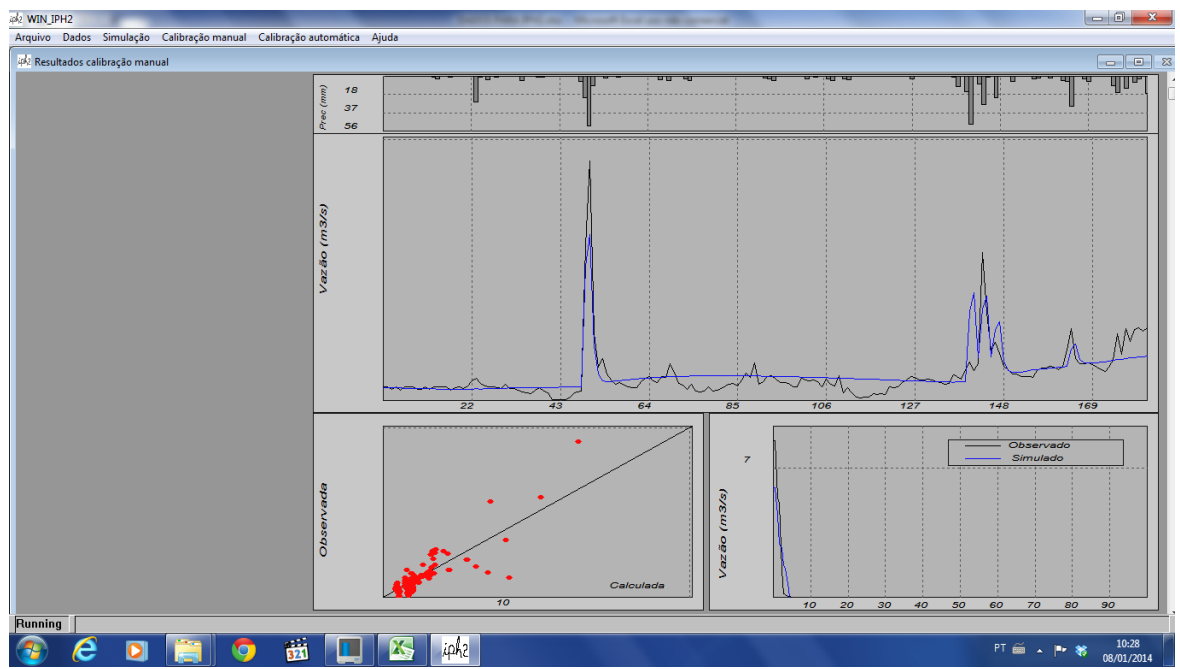

Figure 2: Model screen after calibration. 
To evaluate the calibration of the model some statistical parameters recommended by the literature were used [4]-[8]. The parameters are explained in Table 2.

The value found for the NSE was 0.73 . For the coefficient of determination (RSR) the value generated was 0.74 , close to 1 that makes the model by this coefficient as good and satisfactory. The PBIAS found after calibration was -7.44. According to the literature the value is in a range of values less than \pm 10 which classifies the model as very good.

Table 2: Statistical analysis of the results found.

NASH COEFFICIENT - SUTCLIFE

\begin{tabular}{|l|l|l|l|}
\hline NSE & 0.73 & $>0.65$ & VERY GOOD \\
\hline \multirow{2}{*}{ VERY GOOD } & $0.54>$ NSE $>0.65$ & GOOD \\
\cline { 2 - 4 } & $0.5>$ NSE $>0.54$ & SATISFACTORY \\
\hline
\end{tabular}

DETERMINATION COEFFICIENT

\begin{tabular}{|l|l|l|l|}
\hline $\mathrm{R}^{2}$ & 0.74 & 1 & IDEAL \\
\hline \multirow{2}{*}{ GOOD } & NEXT TO 1 & GOOD \\
\cline { 2 - 4 } & $>0.5$ & ACCEPTABLE \\
\hline
\end{tabular}

PERCENTAGE OF TRENDS

\begin{tabular}{|c|l|l|l|}
\hline PBIAS & -7.44 & $< \pm 10$ & VERY GOOD \\
\hline \multirow{3}{*}{ VERY GOOD } & $\pm 10<$ PBIAS $< \pm 15$ & GOOD \\
\cline { 2 - 4 } & $\pm 15<$ PBIAS $< \pm 25$ & SATISFACTORY \\
\cline { 2 - 4 } & PBIAS $> \pm 25$ & UNSATISFACTORY \\
\hline
\end{tabular}

SQUARE ROOT OF MEDIUM QUADRATIC ERROR

\begin{tabular}{|c|c|c|c|}
\hline RMSE & 0.95 & & \\
\hline \multicolumn{2}{|c|}{ SATISFACTORY } & \begin{tabular}{|l|}
\multicolumn{2}{|c|}{ BELOW HALF OF } \\
STANDARD \\
DEVIATION
\end{tabular} & SATISFACTORY \\
\hline
\end{tabular}

STANDARDIZED AVERAGE ERROR

\begin{tabular}{|c|c|c|c|}
\hline RSR & 0.07 & $0<\mathrm{RSR}<0.5$ & VERY GOOD \\
\hline \multirow{3}{*}{\multicolumn{2}{|c|}{ VERY GOOD }} & $0.5<$ PBIAS $<0.6$ & GOOD \\
\hline & & $0.6<$ PBIAS $<0.7$ & SATISFACTORY \\
\hline & & PBIAS $>0.7$ & UNSATISFACTORY \\
\hline \multicolumn{2}{|l|}{ Dpo } & 13.51 & \\
\hline \multicolumn{2}{|l|}{ Dps } & 10.51 & \\
\hline \multicolumn{2}{|c|}{ Correlation QoxQs } & 0.86 & \\
\hline
\end{tabular}


The negative sign of PBIAS indicates that during the calibration of the model the flow rate was overestimated. The RMSE value was 0.95 , which makes, according to the literature, the model as satisfactory, since the standard deviation of the observed data was 13.51 . The value corresponding to half the standard deviation is 6.755 , so the value 0.95 is well below half of the standard deviation. The RSR value found was 0.07 . This value is in the range between 0 and 0.5 (including 0.5), which classifies the model as very good. Finally, the correlation between observed and simulated flows was 0.86 , close to one which, by this coefficient, makes the model satisfactory.

Fig. 3 shows graphically the values of observed and simulated flows. The $\mathrm{x}$ axis represents the flows in $\mathrm{m}^{3} / \mathrm{s}$ and the y axis, the time in days.

It is observed graphically that the simulated flow curve follows the same pattern, with some discordant points, of the observed flow curve. This fact ratifies the values of the statistical coefficients discussed above. Fig. 4 graphically shows the dispersion between the observed and simulated flows.

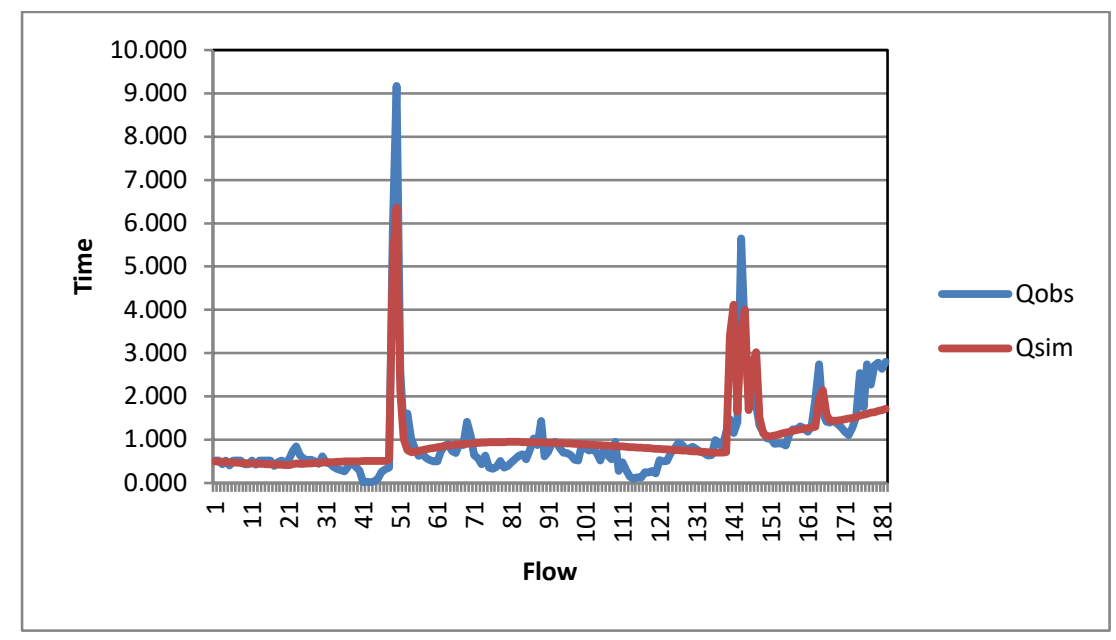

Figure 3: Graph: Observed flow $\times$ simulated flow.

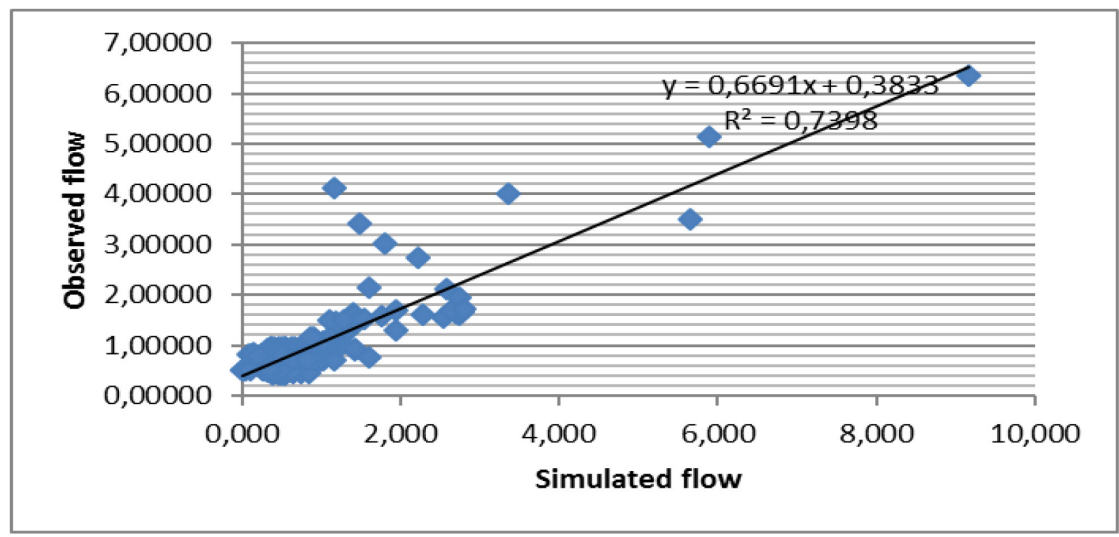

Figure 4: Scatter plot: observed flow $\times$ simulated flow. 
It is observed graphically that only a few points are outside the curve. In general, there is a good correlation between the data ratifying the value of 0.86 found in the correlation between the observed and simulated values.

The validation period used was between January 1, 2011 and March 23, 2011. Statistical coefficients during the validation had a decrease in the performance of the model. The NSE for this period was 0.56 , classified according to the literature as satisfactory. The coefficient of determination was well below a satisfactory result, 0.04. PBIAS was in the range considered very good. The value found for PBIAS was 2.90. The RMSE $=0.25$ is also considered satisfactory. Finally, RSR $=0.10$ also classifies the model as very good.

\section{CONCLUSIONS}

According to the results of the present study, it was possible to conclude that the calibration process for the flow behavior of the Poxim Açu River basin responds positively to what the literature considers satisfactory. The performance of the model during the calibration process was successful with respect to the criteria of performance analysis of the model, which means that the set of input parameters of the model obtained during the calibration process are adequate for the characterization of the hydrological processes of the basin in relation to the flow behavior. The statistics during validation have worsened over the calibration period, but the model can still be considered acceptable for a larger sample of observed flow data. It is concluded that the IPH2 model is an efficient tool for the study of the Poxim Açu basin and it can help as an instrumental in the management of water resources of this basin, mainly in relation to the precarious data of the basin. The model proved to be compatible under these circumstances since it can obtain good results with few input data compared to more complex models.

\section{REFERENCES}

[1] Tucci, C.E., Hydrological Models, Ed. University: Porto Alegre, 1998.

[2] Koch, H. \& Grünewald, U., A comparison of Modeling Systems for the Development and Revision of Water Resources Management Plans. Water Resources Management, 2008. DOI: 10.1007/s11269-008-9333-x.

[3] Silva, M.G., Environmental modeling in the poxim-açu / se river basin and its anthropic relationships, Doctorate Thesis, São Cristovão, Development and Environment Program, Federal University of Sergipe, 2013.

[4] Feyereisen, G.W., Strickland, T.C., Bosch, D.D. \& Sullivan, D.G., Evaluation of swat manual calibration and input parameter sensitivity in the little river watershed. American Society of Agricultural and Biological Engineers, 50, pp. 884-855, 2007.

[5] Green, C.H., Tomer, M.D., Di Luzio, M. \& Arnold, J.G., Hydrologic evaluation of the Soil and Water Assessment Tool for a large tile-drained watershed in Iowa. Transcritions of the ASABE, 49, pp. 413-422, 2006.

[6] Moriasi, D.N., Arnold, J.G., Liew, M.W., Binger, R.L., Harmel, R.D. \& Veith, T., Model evaluation guidelines for systematic quantification of accuracy in watershed simulation. Transactions of the ASABE, 50, pp. 885-900, 2007.

[7] Netto, A.D. \& Bastos, E.A., Agronomic Principles of Irrigation, EMBRAPA: Brazil, 2013.

[8] Singh, J., Knapp, H.V., Arnold, J.G. \& Demissie, M., Journal of the American Water Resources Association, April 2005. http://onlinelibrary.wiley.com/doi/10.1111/j.17521688.2005.tb03740.x/abstract. Accessed on: 14 Dec. 2012. 